\title{
Assessing the Environmental Implications of Industrialized Housing: a Systematic Literature Review
}

\author{
Firehiwot Kedir ${ }^{1 *}$ and Daniel Hall ${ }^{1}$ \\ ${ }^{1}$ Chair of Innovative and Industrial construction, IBI, ETH Zürich, Stefano-Franscini-Platz, \\ Zürich, Switzerland \\ *Corresponding author: Kedir@ibi.baug.ethz.ch
}

\begin{abstract}
Industrialized Housing (IH), also referred to as prefabrication, preassembly, modularization, and/or off-site fabrication, is a growing strategy for constructing housing. IH offers potential for significant reduction of environmental impact in comparison to traditional housing construction. Past research used methods such as environmental impact assessment on given case study buildings or expert's opinions to identify the benefits and drawbacks present on the lifecycle of houses constructed partially or fully using IH methods. Nevertheless, this literature is scattered across several sources and units of analysis. The specific factors of IH that contribute to environmental impact reduction have not been comprehensively reviewed and summarized from design considerations up to the end of life possibilities. In this paper, a systematic literature review is performed on the environmental implications of the industrialized way of constructing residential buildings. From a review of 49 journal publications, this paper identifies 18 key factors that influence the environmental performance of such residential buildings. These factors are categorized into the following lifecycle phases of the IH process: a) system design, b) material design, c) manufacturing and logistics, d) transportation and assembly, e) Operational phase, and f) end of life. Findings reveal the importance of decisions made in design phases such as choice of materials, which in turn show a snowball effect throughout the phases. A final category $-\mathrm{g}$ ) support and hindrance of $\mathrm{IH}$ - includes a discussion of external factors such as building codes and regulatory policies and their impact on $\mathrm{IH}$ performance.
\end{abstract}

\section{KEYWORDS}

Industrialized Construction; Industrialized Housing; Environmental assessment; Residential buildings; Systematic Literature Review

\section{INTRODUCTION}

The construction industry is one of the most energy and material intensive industries in the world. Future global demand for residential buildings requires new thinking about the design and construction of housing. The use of current construction methods and processes will contribute to significant growth in environmental footprint. Due to global housing demand as well as the necessity to alleviate the environmental impacts associated with the construction industry, several remedies to reduce the energy and material requirements for new construction have been proposed by researchers and practitioners. One alternative is Industrialized Housing (IH), sometimes referred to as prefabrication, preassembly, modularization, and/or off-site fabrication. IH uses many concepts from the manufacturing industry, including standardization of elements, high 
quality achievement through factory controlled environment, and more predictable time and cost of construction activities (Keeffe and McHugh 2014). IH firms conceptualize housing as a product similar to outputs from a factory (Gann 1996). In addition, IH requires additional integration of stakeholders in the construction supply chain (Lessing 2006). IH can also represent the use of technology to plan, create, monitor, and communicate. Due to the increased need to improve productivity of the construction industry as well as the mounting concern for the environment, the use of advanced technologies such as those used by IH is strongly needed (Yu et al. 2008). IH generates an opportunity for resource efficiency that leads to diminished environmental impacts.

Although several studies claim that prefabrication improves the construction of buildings, there is lack of detailed scientific literature or case studies that synthesize the environmental benefits of $\mathrm{IH}$ in a holistic way. This paper attempts to do so by conducting a systematic literature review of environmental impact potential associated with IH.

\section{METHODOLOGY}

This paper is a systematic literature review of industrialized construction, housing and sustainability. To conduct the review, two scientific databases - Web of Science and Scopus - were queried using the keywords shown in Figure 1. The search was further refined by filtering the results to only published journal articles. A total of 154 papers were identified. The results were further refined by removing duplicates and inaccessible journals, resulting in 119 papers. The first author then read through the abstract, introduction and conclusion of each article to check for alignment with the thematic scope of this paper. Finally, the remaining 49 papers were read in detail for the review. The publications ranged between the years of 2000 and 2018 with most publications seen in the year 2014. Additionally, 2 papers defined by the authors as seminal literature are included to anchor the context.

\begin{tabular}{|c|c|c|c|c|}
\hline Industrialized Construction & AND & Sustainability & AND & Housing \\
\hline $\begin{array}{c}\text { Prefabrication, Modular } \\
\text { Construction, Pre-built, Digital } \\
\text { fabrication, Dfab, } \\
\text { Mass-produced, Off-site } \\
\text { construction, Prefab, Factory- } \\
\text { built, Additive- manufacturing, } \\
\text { Mass customization, } \\
\text { Industrialized Building system }\end{array}$ & & $\begin{array}{l}\text { Green building, Low } \\
\text { carbon, Climate change, } \\
\text { Zero carbon, } \\
\text { Environment, } \\
\text { Environmental- } \\
\text { Assessment, Life cycle, } \\
\text { LCA, Net zero, Circular } \\
\text { economy }\end{array}$ & & $\begin{array}{l}\text { Residential Building } \\
\text { Apartment }\end{array}$ \\
\hline
\end{tabular}

Figure 1. Keywords and synonyms used on search engines

\section{FINDINGS}

From the reviewed papers, we identify 18 factors that affect the environmental performance of IH. We then group these factors into 7 broader classifications as shown in Figure 2. The first 15 classifications are technically-oriented while the last 3 factors represent the ecosystem in which $\mathrm{IH}$ is implemented. The broad classifications and related sub-factors are presented and discussed in the following sections. 
MOC SUMMIT / MAY 2019

\section{System Design}

System design factors - design efficiency, product modularity, and coordination of super and sub structures - influence the environmental performance of IH during product design. Design Efficiency (A1) refers to design strategies used to reduce the amount of materials used in construction. This includes structural elements such as foundations or super structures such as a wall system. For example, Pujadas-Gispert et al. (2018) and Yu et al. (2008) find that efficient foundation designs such as sloped shapes can be realized with current construction technologies and create the possibility to decrease material usage. In addition, adaptable design strategies can save creation of construction waste at later stages (Dubina et al., 2010).

Product modularity (A2) is a design strategy that aims to create both variable and standardized elements in a product. One of the hurdles in housing construction is customers' desire for a tailormade house and architects' wish for design freedom (Frutos and Borenstein 2003). As highlighted by De Cesaris and Mandolesi (2013), it is difficult to reconcile this mindset with advantages of IH using strategies such as mass customization. To harness the benefits of $\mathrm{IH}$ such as waste reduction through repetitive construction of the same product, the concept of product modularity is proposed and is seen as a paradigm shift (Sferra 2017). Product modularity offers both design flexibility and enough customization of products to achieve environmental benefits of IH. It also provides the possibility to offer catalogue of options to customers and allows developers to identify product variants earlier (De Cesaris and Mandolesi 2013; Nijs et al. 2011). Commonalities between different products can be identified with indices such as the Module Usage Index developed by Da Rocha et al. (2015).

The coordination of super and sub structures (A3) acknowledges material consumption below ground heavily depends on above ground design, hence these structures must be coordinated. Pujadas-Gispert et al. (2018) perform an environmental impact assessment on IH foundation and find that above ground design of housing has significant influence. This aligns with Gorgolewski (2005) and Pujadas-Gispert et al. (2018) who find that the use of timber or other lightweight materials for super structure results in less materials for foundation construction. Nevertheless, coordinating the super and sub structures of buildings has not been given enough attention.

\section{Material design}

The choice of material for construction - specifically the embodied energy, dematerialization, and durability of building components - has a snowballing environmental impact throughout later phases of construction. Embodied energy $(B 1)$ is the sum of energy required to produce a building component. Many authors argue the importance of using timber materials for construction (Aye et al. 2012; Dodoo et al. 2014; Fadai et al. 2014; Lehmann 2012; Nishioka et al. 2000; Tykkä et al. 2010). The capability of wood to store carbon makes it an environmentally-friendly material for IH (Achenbach et al. 2018; Jia Wen et al. 2015). Compared with the embodied energy used to produce conventional building materials such as concrete, aluminum, and brick, timber has much lower production energy demand (Aye et al. 2012; Frenette et al. 2010; Lehmann 2013).

Dematerialization (B2) is the concept of building a structure with less material while still serving the same or similar purpose (Mrkonjic 2007). Dematerialization is one of the reasons considered in choosing innovative construction methods. For example, Pan et al. (2011) find that IH can result in $8-10 \%$ higher usable area in comparison to conventional housing while decreasing the dead load by 1/3-1/2. Furthermore, in the research of Aye et al. (2012) external wall and floor panels are identified to contribute the greatest to the total volume of a building and Dodoo et al. (2014) find 
internal and external walls to contribute greatly to the mass of the building system. Identifying and dematerializing such "hot spots" of overdesign reduces material impacts and has a cascading benefit by reducing transport emissions and foundation sizes.

Durability (B3) refers to building materials and their long-term environmental performance. In the research of Mrkonjic (2007), it is stated that aluminum requires very high amount of energy to be produced. It takes $165-260 \mathrm{MJ}$ of energy to produce a $\mathrm{Kg}$ of aluminum. On the contrary, steel takes 21-25MJ. However, if durability, lightness, recyclability, and other benefits are considered there could be a new standard to look at aluminum and other durable but energy intensive materials. This category had only a limited amount of studies and is likely an area for future development in IH environmental research.

\section{Manufacturing \& Logistics}

The manufacturing and logistics phase of IH integrates additional processes into the conventional construction process. Three factors identified in this category include waste reduction, production system impacts, and green supply chain management. Waste reduction $(C 1)$ occurs through controlled processes of manufacturing building elements in a factory environment. Researchers find that waste is reduced along four different dimensions: (1) Material waste is reduced due to the controlled environment in a factory and mass customization that increases predictability and repetitiveness (Bakri et al. 2011; Boyd et al. 2013; Li et al. 2016; Oleiwi et al. 2017; Pan et al. 2011). This is further supported by case studies (Begum et al. 2010; Pujadas-Gispert et al. 2018). (2) Waste is minimized through the capacity of manufacturing. Factories allow casting of different building elements together such as insulation materials with wall elements and thereby additional mortar is reduced. Additionally, the capacity to produce high-quality end products helps to reduce material consumption during finishing work (Gorgolewski 2005; Jaillon and Poon 2010). Increased quality also means longer service life which contributes to less material use during maintenance (Yu et al. 2008). (3) Factories allow for products to be manufactured using similar equipment and tools. The repetitive use of steel formwork in manufacturing precast elements makes significant material reduction in the of use of formwork (Dong et al. 2015; Jaillon and Poon 2008; Luo et al. 2015; Mohamad Ibrahim et al. 2012). (4) Material waste in the factory can be reused or recycled back into the system instead of being disposed of in landfills (Begum et al. 2010; Boyd et al. 2013; Cao et al. 2015). This point is often overlooked when thinking about material waste in $\mathrm{IH}$. However, IH also requires additional material to ensure elements are not damaged during transportation (Kamali et al. 2018).

The production system impacts (C2) are the environmental impacts driven by the type of production system used. It is widely acknowledged that the introduction of lean principles in construction has created an opportunity to eliminate overproduction and excess inventory (Memari et al. 2014). Traditional production system that is due-date-driven (push) creates unsustainable production flow. The alternative system, a rate driven (Pull) system, produces according to capacity, uses backward scheduling and reduces waste in production (Arashpour et al. 2016; Barriga et al. 2005).

Green supply chain management (C3) addresses the need for key stakeholders such as suppliers, manufacturers and contractors to manage their environmental performance. Luo et al. (2015) find that poor cooperation between different stakeholders tops the list for risk factors in construction industry. In the study of Wu and Low (2014), Green Stock Management (GSM) for prefabrication processes is assessed. Damage to precast elements can occur due to incorrect stacking of elements 
and due to exposure to rain and wind (Luo et al. 2015). Such problems arise from inadequate inventory control systems in which a push demand governs instead of a pull system that depends on actual demand. In addition, integrating the concepts of just-in-time delivery system optimize excess inventory and waste creation (Bae and Kim 2009; Li et al. 2016). The research of Barriga et al. (2005), Jaillon and Poon (2010), and Li et al. (2017) state the use of digital information systems such as RFID and BIM among all stakeholders and processes for information storage and sharing is an opportunity for resource efficiency in IH.

\begin{tabular}{|c|c|}
\hline \multirow[t]{3}{*}{ A. System design } & A1. Efficiency \\
\hline & A2. Product modularity \\
\hline & A3. Coordination of super-and sub-structure \\
\hline \multirow[t]{3}{*}{ B. Material design } & B1. Embodied energy \\
\hline & B2. Dematerialization \\
\hline & B3. Durability \\
\hline \multirow[t]{3}{*}{ C. Manufacturing and Logistics } & $\mathrm{C} 1$. Waste reduction \\
\hline & C2. Production system impacts \\
\hline & C3. Green supply chain management \\
\hline \multirow[t]{2}{*}{ D. Transport and assembly } & D1. Equipment \\
\hline & D2. Location \\
\hline \multirow[t]{2}{*}{ E. Operation } & E1. Operational energy \\
\hline & E2. Supplementary elements \\
\hline \multirow[t]{2}{*}{ F. End of Life } & F1. Reuseability and recyclability \\
\hline & F2. Service based industry \\
\hline \multirow[t]{3}{*}{ G. Support and hindrance of IH } & G1. Customer demand \\
\hline & G2. Building codes \\
\hline & G3. Policies and incentives \\
\hline
\end{tabular}

Figure 2. Industrialized Housing construction and environmental potentials

\section{Transport and assembly of elements}

Transporting elements to site and assembling them onsite is also an integral part of IH and contributes to environmental impacts through the equipment used and the location of the factory and site. Equipment (D1) addresses the energy consumed by equipment used during transport and assembly of IH elements. Energy consumption associated with hoisting prefabricated elements with equipment such as tower cranes is more efficient than those used in the traditional construction sites (Cao et al. 2015). This is due to less frequency of use for equipment as bigger elements are transported for a shorter duration of time, compared to transporting smaller elements over a longer duration of time in traditional construction. Jia Wen et al. (2015) find that the usage of cranes was eight months for an IH project compared to one year for cast-in-situ concrete. In 
addition, energy use during construction works on site in extreme conditions such as winter time is lower for IH than conventionally constructing structures as duration of construction works is shorter (Yu et al. 2008). The type of materials used in constructing buildings also affect the energy required from equipment (Pan et al., 2011). Conversely, some researchers argue that the regular need of cranes to lift components is seen as a downside to the environmental impact of IH (Luo et al. 2015).

Location (D2) is the impact associated with transporting building elements (Dong et al. 2015; Jaillon and Poon 2008; Mohamad Ibrahim et al. 2012; Oleiwi et al. 2017; Pujadas-Gispert et al. 2018; Tonelli and Grimaudo 2014; Yu et al. 2008). The main issue is the delivery distance of the elements. Transportation of building elements accounted for $20 \%$ of environmental impact in a given case study of Achenbach (2018). It is also supported by Bae and Kim (2009) where transportation for an IH project accounted for $18 \%$ carbon emission versus $12 \%$ for a conventional project. Moreover, transportation planning and efficiency is crucial. Compared with volumetric building elements, flat pack systems perform better with transportation due to the flexibility and lower volumes of sorting and transporting (Gorgolewski 2005; Sousa 2013).

\section{Operational phase}

The performance of IH in operational phase is discussed in two main factors: operational energy and supplementary elements. Operational energy (E1) is energy consumed during use phase of buildings. Regarding E1, authors have differing results. Research by Aye et al. (2012) finds that the operational energy of $\mathrm{IH}$ is similar to operational energy and emissions simulations of conventional buildings. In contrast, Rodrigues et al. (2016) and Tonelli and Grimaudo (2014) find the use of lightweight materials in IH reduces the thermal mass of the building. Depending on the location of the building, this could have positive or negative energy performance. Lightness of building structures also means insulation demands are higher in which case, more energy in the use phase of the building (Mrkonjic 2007).

Integrating supplementary elements (E2) is the concept of adding elements that are not considered core to the functionality of a building such as solar panels to reduce the operational energy. Whether buildings are constructed with modular steel or wood elements if PV systems are used, conventional operational energy demands of buildings are significantly reduced (Bukoski et al. 2017; De Cesaris and Mandolesi 2013; Shao et al. 2016).

\section{End of Life (EOL)}

The EOL is often considered the final phase of a building's lifetime, but it can be crucial in making sure environmental impacts are reduced through concepts of reusability and recyclability and service-based industry. Reusability and recyclability $(F 1)$ are the potential of housing structures to be reused or recycled for further use. Conventional housing is a complex system that is difficult to separate building elements. The reusability of a building depends on first, the initial design. In the case of volumetric construction, it is possible to reuse buildings without destroying elements (Boyd et al. 2013; Gorgolewski 2005). Manufactured elements can be easily disassembled not only for EOL of buildings but also in the unfortunate events of fire or simple reasons such as relocation. Second, on the material used, timber is seen as having higher EOL possibilities (Dubina et al. 2010; Lehmann 2013) Contrary to the enormous energy intensive process it takes to produce aluminum, it has a high recyclability rate (Mrkonjic 2007). The savings of energy from reusing the materials lie for steel at $81 \%$, timber at $69.1 \%$ and concrete at $32.3 \%$ (Aye et al. 2012). Nevertheless, EOL stage of a building is one of the least considered when designing a building (Jaillon and Poon 2010). 
Service-based industry $(F 2)$ refers to industry structure transformation from products to services. Even if the EOL possibilities of aluminum or other material used in IH are designed to be dismantled, the recyclability of the structures is not guaranteed unless there is a designated responsible party. The concept of servitization addresses the fact that houses can be constructed and handed out to clients but permanent responsibility is given to manufacturer or a third-party to maintain as well as dismantle the structure. Such industry structures can enable circular economy principles (Mrkonjic 2007).

\section{Support and hindrance of IH Application}

Although factors mentioned in previous sections are important, the ecosystem in which IH is placed also plays a crucial role in boosting sustainable practices. Parts of the ecosystem identified are customer demand, building codes, and policies and incentives. Customer demand (G1) is the end-users requirements and desires to buy the housing. One of the key elements mentioned in driving or impeding innovative and industrial construction is customers' need for sustainable and affordable housing (Dubina et al. 2010; Shao et al. 2016; Tykkä et al. 2010; Wherry and Buehlmann 2014). The willingness to pay (WTP) for building elements that result in a direct financial benefit with a lower initial cost - such as LED Lighting - is high. When it comes to integrating prefabricated elements, the willingness is lower due to higher initial cost. However, in the study, researchers were surprised to find a higher WTP than anticipated (e.g. Yau et al. 2014).

Building codes (G2) are the regulatory requirements placed on materials and designs, often at the state or municipality level. Building codes should accommodate the change in construction materials and methods (Lehmann 2012; Pujadas-Gispert et al. 2018; Zhang et al. 2014). In the case of using engineering wood in construction, many codes in the world still have caps on heights of timber buildings. In addition not all timber products have yet developed codes and standards (Lehmann 2013). Design codes are rated as the second most important factor in adopting IH by experts. The majority of these codes currently are not appropriate for further development of IH (Luo et al. 2015).

Policies and incentives (G3) refer to the regulatory and statuary requirements as well as special benefits drafted for housing projects. Regulatory entities play a major role in adopting innovation. This could be through specific requirements on materials or methods (Luo et al. 2015; Rodrigues et al. 2016). Examples of government regulation include those set up by the UK government on reducing greenhouse emission by $34 \%$ in 2020 and $80 \%$ by 2050 (Gorgolewski 2005) or by the Malaysian government where housing developers that use greater than $50 \%$ of Industrialized Building System components receive levy exemptions and a minimum requirement in using IBS is set (Begum et al. 2010; Oleiwi et al. 2017). A top-down approach which involves imposing mandatory codes for developers has been found to be less efficient. Studies find better incentive structures work when a government is loosely involved through subsides or letting the market take off through systems such as green labeling (Sferra 2017; Yau et al. 2014).

\section{DISCUSSION AND CONCLUSION}

So far, much of the IH research examines outcomes on performance such as cost and time. However, this review finds that the potential of IH to reduce environmental impact is also present in the literature. This paper reviews 49 journal publications on IH and environmental impacts. From this review, we identify 18 key factors that influence the environmental performance of IH. These factors can be grouped into the following categorizations: a) system design, b) material 
design, c) manufacturing and logistics, d) transportation and assembly, e) operational phase, f) end of life, and g) support and hindrance of IH. This paper takes a holistic approach and finds that the total scope of environmental impacts can come from a broad scope of factors. For example, it can be through the technological advancement such as Computer Numerical Control(CNC) machines (Da Rocha et al. 2015; Tonelli and Grimaudo 2014), through digital information that allows tracking materials along the supply chain, or through production efficiency that reduces waste. Overall, we find that the associated environmental impacts of $\mathrm{IH}$ are an improvement to conventional methods, although there are some exceptions.

Furthermore, this review finds that in order to adopt $\mathrm{IH}$ as an alternative method to design and build structures, technical advancement needs to match the current ecosystem of the construction industry. Developers tend to lack desire to go beyond regulatory or statuary requirements and hence full benefits of IH are not achieved unless supporting policies, incentives or requirements are in place (Pan et al. 2012). In addition, current business models, building codes and customer's perception might be possible for further adaptation. Findings of the paper underline the wide range of aspects that influence the environmental performance of IH. Further research is needed for development of the categorization presented here. In addition, additional case studies can be undertaken to validate and enrich the findings developed here.

\section{REFERENCES}

Achenbach, H., Wenker, J. L., and Rüter, S. (2018). "Life cycle assessment of product- and construction stage of prefabricated timber houses: a sector representative approach for Germany according to EN 15804, EN 15978 and EN 16485." European Journal of Wood and Wood Products, Springer Berlin Heidelberg, 76(2), 711-729.

Arashpour, M., Wakefield, R., Blismas, N., and Abbasi, B. (2016). "Quantitative Analysis of RateDriven and Due Date-Driven Construction: Production Efficiency, Supervision, and Controllability in Residential Projects." Journal of Construction Engineering and Management, 142(1), 05015012.

Aye, L., Ngo, T., Crawford, R. H., Gammampila, R., and Mendis, P. (2012). "Life cycle greenhouse gas emissions and energy analysis of prefabricated reusable building modules." Energy and Buildings, Elsevier B.V., 47, 159-168.

Bae, J.-W., and Kim, Y.-W. (2009). "Assessing the Environmental Impacts of Lean Supply System: A Case Study of Rebar Supply in High-Rise Condominium Construction Projects." Construction Research Congress 2009, 16(December), 1009-1018.

Bakri, A. F., Zubir, S. S., Samadi, Z., and Osman, H. (2011). "Tailoring the needs for a better living: An urban renewal scheme on low cost housing." WIT Transactions on Ecology and the Environment, 148, 301-312.

Barriga, E. M., Jeong, J. G., Hastak, M., and Syal, M. (2005). "Material Control System for the Manufactured Housing Industry." Journal of Management in Engineering, 21(2), 91-98.

Begum, R. A., Satari, S. K., and Pereira, J. J. (2010). "Waste generation and recycling: Comparison of conventional and industrialized building systems." American Journal of Environmental Sciences, 6(4), 383-388.

Boyd, N., Khalfan, M. M. A., and Maqsood, T. (2013). "Off-Site Construction of Apartment Buildings." Journal of Architectural Engineering, 19(1), 51-57.

Bukoski, J. J., Chaiwiwatworakul, P., and Gheewala, S. H. (2017). "The Life Cycle Assessment of an Energy-Positive Peri-Urban Residence in a Tropical Regime." Journal of Industrial Ecology, 21(5), 1115-1127. 
Cao, X., Li, X., Zhu, Y., and Zhang, Z. (2015). "A comparative study of environmental performance between prefabricated and traditional residential buildings in China." Journal of Cleaner Production, Elsevier Ltd, 109, 131-143.

De Cesaris, A., and Mandolesi, D. (2013). "Modular, sustainable and customized: Projects for the contemporary dwelling." Open House International, 38(3), 39-47.

Dodoo, A., Gustavsson, L., and Sathre, R. (2014). "Lifecycle primary energy analysis of lowenergy timber building systems for multi-storey residential buildings." Energy and Buildings, Elsevier B.V., 81, 84-97.

Dong, Y. H., Jaillon, L., Chu, P., and Poon, C. S. (2015). "Comparing carbon emissions of precast and cast-in-situ construction methods - A case study of high-rise private building." Construction and Building Materials, Elsevier Ltd, 99, 39-53.

Dubina, D., Ungureanu, V., Ciutina, A., Tuca, I., and Mutiu, M. (2010). "Sustainable detached family house - case study." Steel Construction, 3(3), 154-162.

Fadai, A., Fuchs, M., and Winter, W. (2014). "Wood-Based Construction for Multi-story Buildings: Application of Cement Bonded Wood Composites as Structural Element." Materials and Joints in Timber Structures, Springer Netherlands, Dordrecht, 471-484.

Frenette, C. D., Bulle, C., Beauregard, R., Salenikovich, A., and Derome, D. (2010). "Using life cycle assessment to derive an environmental index for light-frame wood wall assemblies." Building and Environment, Elsevier Ltd, 45(10), 2111-2122.

Frutos, J. D., and Borenstein, D. (2003). “Object-Oriented Model for Customer-Building Company Interaction in Mass Customization Environment." Journal of Construction Engineering and Management, 129(3), 302-313.

Gann, D. M. (1996). "Construction as a manufacturing process? Similarities and differences between industrialized housing and car production in Japan." Construction Management and Economics, 14(5), 437-450.

Gorgolewski, M. T. (2005). "The potential for prefabrication in UK housing to improve sustainability." Smart \& Sustainable Built Environments Smart \& Sustainable Built Environments, A. C. Yang, J., Brandon, P.S., Sidwell, ed., 17.

Jaillon, L., and Poon, C. (2010). "Design issues of using prefabrication in Hong Kong building construction." Construction Management and Economics, 28(10), 1025-1042.

Jaillon, L., and Poon, C. S. (2008). "Sustainable construction aspects of using prefabrication in dense urban environment: A Hong Kong case study." Construction Management and Economics, 26(9), 953-966.

Jia Wen, T., Chin Siong, H., and Noor, Z. Z. (2015). “Assessment of embodied energy and global warming potential of building construction using life cycle analysis approach: Case studies of residential buildings in Iskandar Malaysia." Energy and Buildings, Elsevier B.V., 93, 295-302.

Kamali, M., Hewage, K., and Milani, A. S. (2018). "Life cycle sustainability performance assessment framework for residential modular buildings: Aggregated sustainability indices." Building and Environment, Elsevier, 138(April), 21-41.

Keeffe, G., and McHugh, I. (2014). "IDEAhaus: A Modular Approach to Climate Resilient UK Housing." Buildings, 4(4), 661-682.

Lehmann, S. (2012). Sustainable construction for urban infill development using engineered massive wood panel systems. Sustainability.

Lehmann, S. (2013). "Low carbon construction systems using prefabricated engineered solid wood panels for urban infill to significantly reduce greenhouse gas emissions." Sustainable Cities 
and Society, Elsevier B.V., 6(1), 57-67.

Lessing, J. (2006). Industrialised House-Building, Concept and Processes.

Li, C. Z., Hong, J., Xue, F., Shen, G. Q., Xu, X., and Luo, L. (2016). "SWOT analysis and Internet of Things-enabled platform for prefabrication housing production in Hong Kong." Habitat International, Elsevier Ltd, 57, 74-87.

Li, C. Z., Zhong, R. Y., Xue, F., Xu, G., Chen, K., Huang, G. G., and Shen, G. Q. (2017). "Integrating RFID and BIM technologies for mitigating risks and improving schedule performance of prefabricated house construction." Journal of Cleaner Production, Elsevier Ltd, 165, 1048-1062.

Luo, L., Mao, C. L. S., and Li, Z. (2015). "Risk factors affecting practitioners' attitudes toward the implementation of an industrialized building system: Acase study from China."

Memari, A. M., Asce, F., Huelman, P. H., Iulo, L. D., Laquatra, J., Martin, C., Mccoy, A., Nahmens, I., Williamson, T., and Asce, F. (2014). "Residential Building Construction: State-of-the-Art Review." Journal of Architectural Engineering, 20(4), 1-38.

Mohamad Ibrahim, M. M. Al. N., Taherkhani, R. ., Saleh, A. L. ., and Shaiful Amri, M. (2012). "Exploring the potential of using Industrialized Building System for Floating Urbanization by SWOT Analysis." Journal of applied sciences.

Mrkonjic, K. (2007). "Environmental aspects of use of aluminium for prefabricated lightweight houses: Dymaxion house case study." Journal of Green Building, 2(4), 130-136.

Nijs, J. C., Durmisevic, E., and Halman, J. I. M. (2011). "Interface design for open systems building." Open House International, 36(1), 35-43.

Nishioka, Y., Yanagisawa, Y., and Spengler, J. D. (2000). "Saving Energy versus Saving Materials, Life-Cycle Inventory Analysis of Housing in a Cold Climate Region of Japan." Journal of Industrial Ecology, 4(1), 119-135.

Oleiwi, M. Q., Che-ani, A. I., Mohamed, M. F., and Raman, S. N. (2017). "Sustainability of Industrialised Building System for Housing in Malaysia." Proceeding of the Institution of Civil Engineers-Engineering Sustainability, 171(2009), 1-10.

Pan, W., Dainty, A. R. J., and Gibb, A. G. F. (2012). "Establishing and Weighting Decision Criteria for Building System Selection in Housing Construction." Journal of Construction Engineering and Management, 138(11), 1239-1250.

Pan, Y., Wong, F. K. W., and Hui, E. C. M. (2011). "Application of Industrialized Housing System in China: A Chongqing Study." Modeling Risk Management in Sustainable Construction, 161-168.

Pujadas-Gispert, E., Sanjuan-Delmás, D., and Josa, A. (2018). "Environmental analysis of building shallow foundations: The influence of prefabrication, typology, and structural design codes." Journal of Cleaner Production, 186, 407-417.

Da Rocha, C. G., Formoso, C. T., and Tzortzopoulos, P. (2015). “Adopting Product Modularity in House Building to Support Mass Customisation.” Sustainability, 7, 4919-4937.

Rodrigues, L., Sougkakis, V., and Gillott, M. (2016). "Investigating the potential of adding thermal mass to mitigate overheating in a super-insulated low-energy timber house." International Journal of Low-Carbon Technologies, 11(3), 305-316.

Sferra, A. S. (2017). "Emergency: innovative prefabricated construction components for an ecosolidarity architecture ." Techne, 14, 330-336.

Shao, J., Chen, H., and Zhu, T. (2016). "Solar energy block-based residential construction for rural areas in the West of China." Sustainability (Switzerland), 8(4).

Sousa, J. (2013). "Application of prefabricated panels for the energy retrofit of Portuguese 
residential buildings facades: A case study." Archives of Civil Engineering, 59(3), 337-357. Tonelli, C., and Grimaudo, M. (2014). "Timber buildings and thermal inertia: Open scientific problems for summer behavior in Mediterranean climate." Energy and Buildings, Elsevier B.V., 83, 89-95.

Tykkä, S., McCluskey, D., Nord, T., Ollonqvist, P., Hugosson, M., Roos, A., Ukrainski, K., Nyrud, A. Q., and Bajric, F. (2010). "Development of timber framed firms in the construction sector - Is EU policy one source of their innovation?" Forest Policy and Economics, Elsevier B.V., 12(3), 199-206.

Wherry, G., and Buehlmann, U. (2014). "Product life cycle of the manufactured home industry." BioResources, 9(4), 6652-6668.

Wu, P., and Low, S. P. (2014). "Barriers to achieving green precast concrete stock management A survey of current stock management practices in Singapore." International Journal of Construction Management, Taylor \& Francis, 14(2), 78-89.

Yau, Y., Chiu, S. M., and Lau, W. K. (2014). "Economising subsidies for green housing features: A stated preference approach." Urbani Izziv, 25(2), 107-118.

Yu, H., Al-Hussein, M., Nasseri, R., and Cheng, R. J. (2008). "Sustainable precast concrete foundation system for residential construction." Canadian Journal of Civil Engineering, 35(2), 190-199.

Zhang, X., Skitmore, M., and Peng, Y. (2014). "Exploring the challenges to industrialized residential building in China." Habitat International, Elsevier Ltd, 41, 176-184. 